ANL-5239

Instrumentation

ARGONNE NATIONAL LABORATORY

$2 j=$

P. O. Box 299

Lemont, Illinois

POTTING OF PHOTOMULTIPLIER TUBES

by

R. K. Swank and J. S. Moenich

INSTRUMENT RESEARCH AND DEVELOPMENT DIVISION

February 1954

Operated by The University of Chicago

under

Contract W-31-109-eng-38 


\section{DISCLAIMER}

This report was prepared as an account of work sponsored by an agency of the United States Government. Neither the United States Government nor any agency Thereof, nor any of their employees, makes any warranty, express or implied, or assumes any legal liability or responsibility for the accuracy, completeness, or usefulness of any information, apparatus, product, or process disclosed, or represents that its use would not infringe privately owned rights. Reference herein to any specific commercial product, process, or service by trade name, trademark, manufacturer, or otherwise does not necessarily constitute or imply its endorsement, recommendation, or favoring by the United States Government or any agency thereof. The views and opinions of authors expressed herein do not necessarily state or reflect those of the United States Government or any agency thereof. 


\section{DISCLAIMER}

Portions of this document may be illegible in electronic image products. Images are produced from the best available original document. 


\title{
POTTING OF PHOTOMULTIPLIER TUBES
}

by

Robert K. Swank and John S. Moenich

\begin{abstract}
This report details the materials used and the manipulations employed for the potting of photomultiplier tubes.
\end{abstract}

\section{PREPARATION OF THE PARTS AND MATERIALS}

Light Guide

The guide is made of Lucite, a du Pont product. For use with the RCA -5819 photomultiplier, the guide is $1 / 4$ in. thick, $1-3 / 4$ in. indiameter, and machined or molded to fit the curvature of the top of the tube. For the DuMont-6292, the guide may be cut from sheet Lucite. It is $1 / 8$ in. thick and $1-5 / 8 \mathrm{in}$. in diameter.

The DuMont tube actually requires no light guide because it already possesses a flat surface, but the guide does serve a secondary role as an insulator against leakage of current from the cathode surface through the crystal can to the ground. Leakage of current will cause dark current pulses and electrolysis of the glass which will destroy the cathode surface.

\section{Preparations for Cementing}

The lower $1 / 4$ in. of the tube base is to be roughened all the way around by rubbing gently with emery cloth. Similarly, the inside of the aluminum cylinder is to be roughened for about 1 in. at that end to which the tube base is to be attached. This roughening will improve the adhesion of the cement to both tube base and aluminum cylinder and thus increase the strength of the joint.

\section{Assembly of Light Guide and Tube}

Insert the tube in a base. A 5819 tube socket will serve excellently. Clean the cathode (upper) surface of the tube thoroughly with acetone. Place the tube in upright position in an oven which is held at approximately $70^{\circ} \mathrm{C}$. On the cathode surface place a small piece (about a $3 / 8$ in. cube) of clean, clear polyvinylacetate. Supply a slight excess to assure successful completion of the step; the excess is easy to remove. 
Support a half of a Petrie dish above the polyvinylacetate and tube to prevent dust from accumulating upon them.

While waiting for the polyvinylacetate to become sufficiently pliable, clean the light guide with ethyl alcohol, dry it with Kleenex to remove any cloudiness, and place it in the oven alongside the tube. Ten minutes heating of the guide should warm it sufficiently to secure good adhesion of the parts by the polyvinylacetate.

When the polyvinylacetate is melted and the light guide is warm enough, remove the parts from the oven, blow off (with the breath) any dust accumulated on the light guide and place the guide on the tube. With a small piece of plate glass, apply gentle pressure to the light guide and gradually work the excess of polyvinylacetate from between the guide and the tube. Use of the plate glass provides uniform distribution of the pressure and avoids the distortion which may result by direct use of the fingers. Distortion will result in a nonuniform layer of wetting agent between crystal and light guide surface and allow this wetting agent to flow out more readily when tube is used in horizontal position.

If need be, the parts may be returned to the oven to be rewarmed before completing the assembly.

While the polyvinylacetate is still soft, peel away, with the fingers, as much as possible of the excess which has been squeezed from the joint. Also, center the light guide upon the tube.

Let the assembly cool. When the polyvinylacetate has hardened, wipe away the remaining excess of polyvinylacetate, using Kleenex wetted with ethyl alcohol. Do not use acetone for this purpose, as it will attack Lucite.

The top surface of the light guide should now be covered with masking tape and this covering should be retained in place until the "potting" is completed, thereby protecting the guide from marring, scratching, and solvents.

To prevent loss of light through the edge of the light guide, the edge is painted with three coats of "Tygon" white plastic paint. Approximately 1 hr should be allowed between successive applications of the paint. Ease of application and tenacious adherence to the Lucite make this "Tygon" paint desirable for this step in the potting procedure. But improved reflecting power is desirable. The "Tygon" paint is soluble in acetone; therefore, for any cleaning operation, use ethyl alcohol instead of acetone. 
Current Leakage

Although the light guide acts as an insulator against current leakage, another preventative is provided by painting a ring of colloidal silver about the base of the light guide. A strip is then painted from this ring down the side of the tube to pin 14, the cathode. (Be sure that the surface is well cleaned with ethyl alcohol before this painting.)

Use a thin sheet of polystyrene, held in place with Scotch Electrical Tape No. 33, to cover the silver paint strip running down the side of the tube base, to insulate it from the aluminum can which is to be cemented to the base. The tape should be placed so that most of the circumference of the lower portion of the tube base can be contacted with the rubber cement. A suitable source of polystyrene sheet is a polystyrene capacitor.

The Mu-Metal Shield

To prevent interference of magnetic fields with the flow of electrons from the cathode surface to the first dynode of the photomultiplier, a Mumetal shield is placed about the tube. Electrical Tape No. 33 is wrapped around the envelope of the tube about $3 / 4$ in. above the base and also approximately the same distance below the top of the tube, so that the $\mathrm{Mu}-$ metal shield can be positioned properly. This is done by sliding the Mu-metal shield over the tape and then slipping 2 of the Bakelite rings (such as used in potting) over the Lucite light guide. The Mu-metal shield is then so positioned that, with the lower one of the Bakelite rings resting on the upper edge of the Mu-metal shield, the top surface of the upper ring is flush with the upper surface of the light guide. Scotch Electrical Tape No. 33 is then wrapped around the lower edge of the Mu-metal shield to hold it fixed in this position.

Assembly before Potting

The assembly consists of an aluminum cylinder, the upper end of which is fastened to a threaded brass ring, a Bakelite ring to center the tube within the cylinder and thus to "float" the tube within the confines of the cylinder, and a threaded aluminum collar which positions the crystal relative to the tube, retains this crystal, and, with the help of a sponge rubber gasket, completes the light-tightness of the assembly. Specifications for parts of the assembly may be obtained from ANL Drawing No. CS -1882 .

Note that the inside diameter of the Bakelite ring is proportioned to the outside diameter of the light guide, being larger for the RCA-5819 than for the DuMont-6292. This is the only difference in the potting parts required for both RCA-5819 and DuMont 6292 photomultiplier tubes. 
Potting the Tube

The upper end of the aluminum cylinder is turned down on the outer side and a brass ring, threaded on its outer side, is secured at this place. the brass ring projecting slightly beyond the aluminum cylinder. The small recess, formed by the projection of the brass ring beyond the aluminum cylinder, is filled with rubber cement. Into this cement-filled recess a Bakelite ring is set. Separately spread a thin film of the rubber cement. around the wall of the upper half of the light guide which has already been attached to the phototube. Then insert the light guide and tube through the lower end of the aluminum cylinder until the light guide protrudes through the center of the Bakelite ring. Now take a second Bakelite ring of the same size, slip over the light guide, turn the entire assembly upside down, and place it onto a flat surface. The second Bakelite ring acts merely as a spacer and assures that the light guide will protrude above the first Bakelite ring, simplifying the removal of crystals from the light-guide surface. A piece of Kleenex between the tube and the flat surface will prevent the assembly from sticking to the flat surface. During this operation the tube is held as rigidly as possible with one hand to prevent the first Bakelite ring from being forced out of the recess. The other hand places the second Bakelite ring and guides the opposite end of the assembly until it has been placed in the desired position with the light guide end of the tube down upon the flat surface.

The tube base is now centered in the aluminum cylinder and braced in this position with pieces of cork or of electrical tape. Then the opening is filled with rubber cement, foreing it in with a spatula: a depth of $1 / 4$ in. being sufficient. A greater depth is not advisable since the other parts of the assembly can be reused if the tube has to be replaced. The rubber cement will harden overnight. The process can be accelerated by adding more hardener to the base agent, but experience has proven that too much hardener decreases the adhering properties. When the rubber cement has hardened, the excess can be trimmed away with a razor blade. Any which remains can be removed with Kleenex wetted with ethyl alcohol. Acetone can be used only with extreme caution near the light guide, since the acetone will destroy its surface.

A diagram of the assembled tube is attached as Drawing IRD -605 . (Figure 1) A bill of materials is attached also. ANL Drawing No. CS-1882 supplies specifications for parts of the potting asserably.

The process of "potting" photomultiplier tubes requires that close attention be paid to all of the details. It is essential that all surfaces to which cement is to be applied, be free of dirt and grease.

Safety goggles should be worn at any stage of the process when pressure is applied to the tube, since breaking of the tube would result in possible injury from flying glass. 
Photomultipliers potted by this proceedure have been used successfully at this laboratory for several years. They have proved useful and reliable under laboratory conditions. However, their use outside the laboratory is limited by the failure of the polyvinylacetate cement to remain sufficiently fluid below about $40^{\circ} \mathrm{F}$. This may result in a loss of optical contact between the light guide and photomultiplier if the assembly is used or stored for long periods below $40^{\circ} \mathrm{F}$. Attempts to find an adhesive which would remain plastic at low temperatures have been unsuccessful.

\section{LIST OF MATERIAILS}

Aluminum cylinder, $2-15 / 32$ in. diameter, $4-7 / 8$ in. long, 1/16 in. thickness. Aluminum collax, threaded.

Brass ring, threaded.

Mu-metal shield, 0.025 in. gage, Allegheny hydrogen-annealed, 2-1/16 in. inside diameter x 3-1/4 in. long. Made by Allegheny Ludlum Steel. Corporation.

Photomultiplier tube - RCA-5819 or DuMont-6292.

Tube base - RCA-5819 tube socket.

Lucite lightguide $-1 / 8$ in. thick $\times 1-5 / 8$ in. diameter for DuMont tube. $1 / 4$ in. thick $\times 1-3 / 4$ in. diameter for RCA tube.

Polyvinylacetate "Vinylite Plastic, AYAC Blend 3695", Obtainable from The Bakelite Company, P. O. Box N, South Charleston 3, West Virginia. The order number is BVS-3900. This must be clear, white, soft enough to be workable at a temperature not detrimental to the phototube.

Rubber cement - Minnesota Mining and Manufacturing Company, Detroit, Michigan. Base agent - EC-801 and Hardener - EC-807: Mix 4 parts base with 1 part hardener shortly before use. Keep base agent under refrigeration when stored.

Scotch Electrical Tape No. 33

Gasket, sponge rubber

Ring, Bakelite. Inside diameter depends upon outside diameter of light guide used.

Masking tape

Tygon paint, white plastic, U. S. Stoneware Co., Akron, Ohio.

Polystyrene sheet, thin.

Acetone.

Ethyl alcohol.

Colloidal silver paint. 
Oven, controllable at $70^{\circ} \mathrm{C}$.

Plate glass - small piece ( $1 / 4$ in. $x 3$ in. $x 3$ in.)

Petrie dish

Spatula

Razor blade

A flat surface (Table top or the like)

Emery cloth

Cork - several small pieces

Kleenex cleansing tissues

Safety glasses (goggles)

ANL Drawing No. CS-1882 


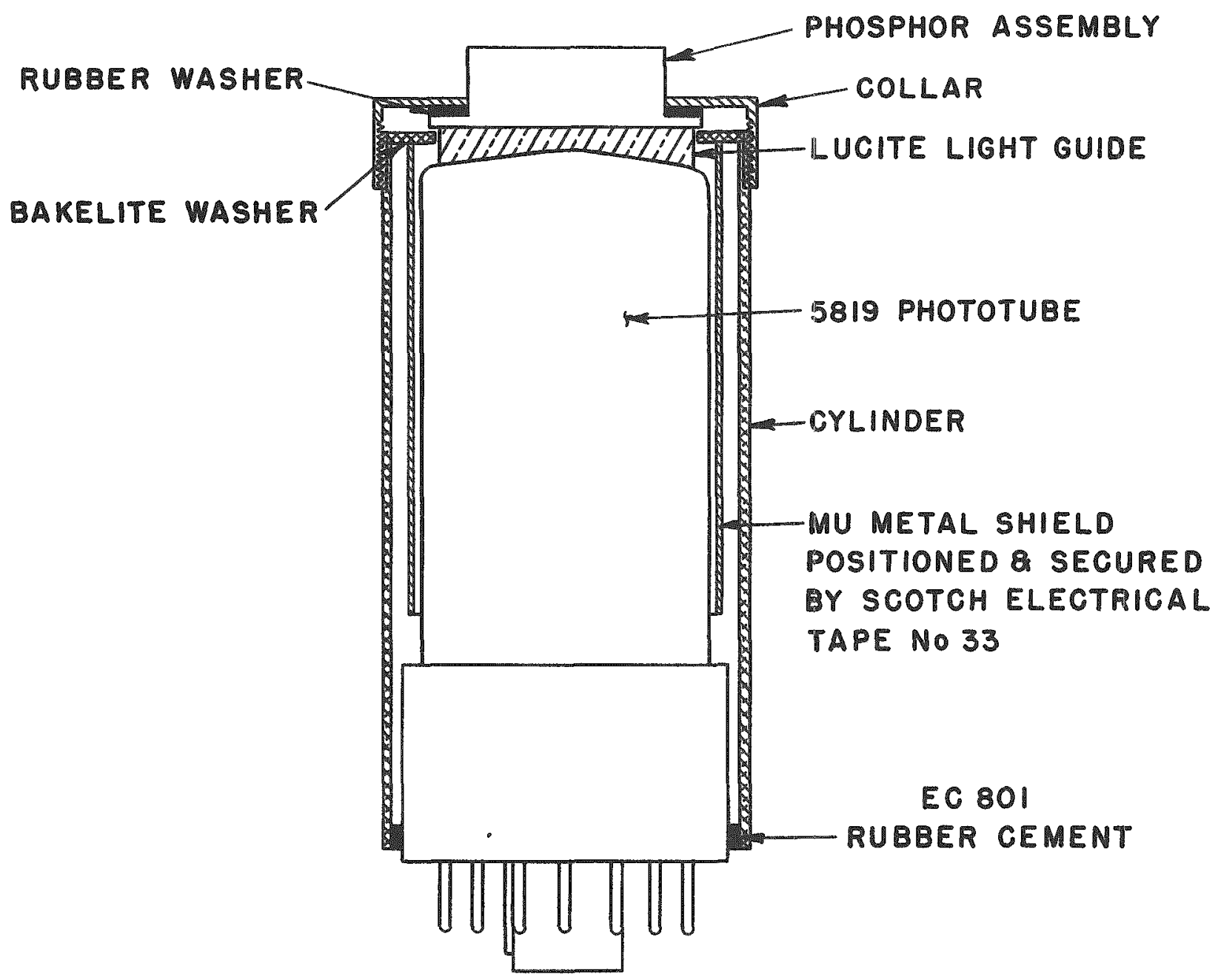

$100-605$

$2 \cdot 11-34$

6.6

FIGURE I 